\title{
A ESCOLA E A EXCLUSÃO
}

\author{
FRANÇOIS DUBET \\ École des Hautes Études en Sciences Sociales - Cadis \\ Université Victor Segalen 2 - Bordeaux \\ francois.dube@sociologie.u-bordeaux2.fr \\ Tradução: Neide Luzia de Rezende \\ RESUMO
}

\begin{abstract}
Para abordar com serenidade as relações entre educação e exclusão importa primeiro distinguir o que depende da exclusão social e de seus efeitos na escola, da exclusão escolar propriamente dita. A situação atual é, sem dúvida, definida pelo reforço dos processos sociais de exclusão com o aumento das desigualdades e do desemprego. Entretanto, o fenômeno mais marcante e mais paradoxal é o desenvolvimento da exclusão escolar propriamente dita, como conseqüência de uma vontade de interrogação inigualada. Quanto mais a escola intensifica o seu raio de ação, mais ela exclui, apesar das politicas que visam a atenuar esse fenômeno. Nesse contexto, a exclusão não é apenas uma categoria do sistema e dos processos globais, é também uma das dimensões da experiência escolar dos alunos.

EDUCAÇÃO - PROCESSO DE INTERAÇÃO SOCIAL - EXCLUSÃO SOCIAL
\end{abstract}

\section{ABSTRACT}

SCHOOLSAND EXCLUSION. In order to treat in an unbiased way the relationship between education and exclusion we first of all have to distinguish between what specifically concerns social exclusion and its resulting effects on school life, and exclusion strictly speaking at school. The present day situation is undoubtedly by the social process of exclusion being reinforced by the rise in inequalities due to unemployment. However the most striking and paradoxical phenomenon is the development of exclusion strictly speaking as a consequence of a determined unprecedented questioning of schools. The more schools develop their ascendancy the more they exclude, in spite of policies which try to attenuate the phenomenon. In this context exclusion is not simply a category of the system and global processes, but also one of the dimensions of pupils' experience of schooling. EDUCATION - INTERACTION PROCESS - SOCIAL EXCLUSION

Este artigo foi publicado originalmente em francês na revista Éducation et Sociétés, n.5, p.43-57, 2000/200l. 
O tema da escola e da exclusão não é dos mais simples quando evitamos facilidades como a de nos restringir à indignação moral ou à longa descrição das dificuldades encontradas pelos alunos excluídos da escola ou originários de meios já "excluídos". O tema, de fato, remete a toda uma série de problemas que é importante distinguir se quisermos ver a questão de um modo um pouco mais claro e não ceder à moda que busca explicar a exclusão por meio das idéias mais consolidadas sobre a desigualdade das oportunidades escolares. Vários problemas serão aqui abordados.

- O primeiro deles é o lugar da escola numa estrutura social perpassada pelos mecanismos de exclusão. É importante saber o que se refere à sociedade e o que se refere à escola. Ou seja, qual é o lugar da escola numa estrutura social que desenvolve processos de exclusão?

- O segundo tipo de problemas concerne à análise dos mecanismos propriamente escolares que engendram uma segmentação escolar, determinante na formação dos percursos de exclusão.

- Pode-se, por fim, evocar as conseqüências dessa mutação estrutural sobre a natureza das próprias experiências escolares, a dos professores e a dos alunos.

Na verdade, esses três tipos de problemas se aliam na construção de um objeto muitas vezes reduzido à simples descrição das dificuldades sociais e escolares do público em "dificuldade", que também é um público "difícil".

\section{DA EXCLUSÃO SOCIAL À EXCLUSÃO ESCOLAR: Um processo duplo}

Somos geralmente confrontados com duas retóricas ideológicas que pontuam o debate sobre a escola e a exclusão.

Para uns, o desemprego e a precariedade dos jovens advêm da falta de adequação entre formação e emprego. A escola produziria uma formação não adaptada às necessidades da economia, produziria muitos diplomas de ensino geral e também diplomas responsáveis por introduzir uma rigidez nociva ao acesso dos jovens ao emprego. Geralmente, essa argumentação se baseia em algumas idéias simples ou na idealização do modelo alemão de formação profissional. Repousa também, às vezes, sobre um estranho silogismo que "demonstra": já que todos os jovens egressos das grandes escolas" ou dos cursos superiores têm um emprego,

Escolas de nível superior de grande prestígio na França, cujo acesso é feito por exame vesti$\operatorname{bular}($ N. da E.). 
bastaria que todos os jovens atingissem esse nível de qualificação para que tivessem um emprego. Estudos como os de Tanguy (1986) já refutaram esse argumento, mostrando seu pequeno alcance. Para dizer de modo analítico, a exclusão social dos jovens não advém só das relações de reprodução.

Para outros, os "defensores" da escola, o sistema educacional é totalmente "inocente" em face da exclusão. Não somente o desemprego dos jovens é independente do sistema de formação, mas todas as dificuldades da escola, a "violência”, a débil motivação dos jovens, vêm de fora, do capitalismo e do mercado. A exclusão social dos jovens decorreria apenas das relações de produção. A referência ao "modelo alemão" é neste caso substituída pela de idade de ouro da escola republicana, em que cada diplomado podia encontrar um emprego correspondente a sua formação. E o mesmo silogismo é usado como socorro: já que as qualificações escolares elevadas protegem do desemprego, é preciso aumentar o nível de qualificação para erradicar o desemprego.

Essa dupla retórica que acusa ora o serviço público, ora o mercado é também uma maneira de não tocar num problema relativamente complexo e "clássico": os elos das "relações de produção", definidas pela produção de riquezas, e as "relações de reprodução", nas quais a escola distribui escalonamentos e oportunidades. Ora, as relações entre esses dois conjuntos foram profundamente transformadas ao longo do século, vinculando estreitamente a escola aos mecanismos de exclusão, sem fazer dela entretanto a "culpada" como alguns pretendem.

\section{A escola preservada da exclusão}

É preciso lembrar a relação muito particular da escola e da sociedade, estabelecida pela escola republicana do final do século XIX: relação caracterizada, de um lado, por uma grande distância entre a escola e a produção, de outro, por uma forte adequação da oferta escolar ao sistema das classes sociais.

Sabemos bem que a escola republicana primeiro foi "escolar". Seus fundadores não se preocupavam com a economia e a formação profissional (Charlot, Figeat, 1985; Lelièvre, 1990; Nicolet, 1982), tampouco os sindicatos operários ou o patronato insistiam nesse sentido. A escola republicana era impelida pelo projeto de instalar uma cidadania nova e pela legitimidade das instituições republicanas. Ela devia instaurar uma consciência racional e um sentimento nacional, uma laicidade capaz de fazer a França entrar na modernidade. As minorias religiosas judias e protestantes, os racionalistas e os positivistas tiveram um papel essencial na construção de uma escola que deveria assegurar o reino dos direitos do homem, da razão e do 
patriotismo. Essa escola ensinava menos a ciência que as belezas da ciência, ela ensinava menos a tecnologia que algumas noções elementares.

O liceu "burguês", de seu lado, ficava centrado nas humanidades e reivindicava a gratuidade do saber contra os conhecimentos diretamente úteis e produtivos (Isambert-Jamati, 1970). A história do liceu é a história de uma longa resistência ao ensino técnico e profissional e de um relegar esse ensino para as carreiras desvalorizadas; um confinamento simbólico, do qual hoje temos muita dificuldade em nos desvencilhar (Prost, 1967). Isso não significa que jamais tenha havido um desejo de adaptação da formação aos empregos e às qualificações profissionais, mas simplesmente que essa função permaneceu sempre marginal. Em conseqüência, a escola francesa foi durante longo tempo preservada do risco de ser diretamente confrontada com os diversos problemas do emprego e da exclusão.

Mas a marca essencial desse sistema era o dualismo escolar e o tipo de recrutamento das diversas clientelas. A escola primária acolhia as crianças do povo, o liceu, aquelas da burguesia, e o ginásio funcionava ao mesmo tempo como uma triagem e como a escola das crianças das camadas médias. Esse modo de recrutamento, dominante até o início dos anos 60, é caracterizado por uma seleção que ultrapassa a escola. Não é diretamente a escola que realiza as grandes operações de distribuição dos alunos, são as desigualdades sociais que comandam diretamente $\mathrm{o}$ acesso às diversas formas de ensino. Uma das conseqüências desse sistema é que a escola aparece justa e "neutra" no seu funcionamento, enquanto as injustiças e as desigualdades sociais é que são diretamente a causa das desigualdades escolares. Num tal sistema, a escola intervém relativamente pouco sobre o destino dos indivíduos, que é, antes de mais nada, um destino social, e, quando intervém, ela o faz sobretudo de maneira "positiva", segundo o modelo da promoção dos melhores alunos egressos do povo: é o modelo do "elitismo republicano". Ou seja, já que é baseada num princípio de reprodução estrutural das desigualdades sociais, essa escola não aparece como um agente ativo da exclusão social. Ela simplesmente não intervém nesse domínio ou o faz de maneira feliz, impedindo que algumas crianças do povo cumpram um destino que lhes estava reservado pelas injustiças sociais. Não era a escola que era injusta, era antes de tudo a sociedade, mesmo se uma e outra eram muito mais "objetivamente" injustas ontem que o são hoje em termos de desigualdade e de distância social.

O malthusianismo escolar protegeu durante longo tempo a escola do processo que acabou fazendo dela um fator de exclusão. É importante lembrar que, até o início da década de 70, os diplomas eram produzidos em quantidade menor ou igual à dos empregos qualificados a que correspondiam. Nos anos 30, a metade dos fran- 
ceses não tinha o certificado de estudos, os bacharéis e os estudantes eram raros e o valor social dos diplomas era garantido pela sua escassez. O ensino profissionalizante oferecido pelos centros de aprendizagem e pelas escolas profissionais de nível médio também controlava o recrutamento a fim de assegurar a absorção de seus egressos. No fundo, todo o sistema funcionava segundo o princípio das grandes escolas, cujo malthusianismo era a melhor garantia de valor. A escola republicana não participava da exclusão social porque a grande maioria dos jovens, numa França operária e camponesa, tinha acesso ao emprego independentemente de suas qualificações escolares. Ninguém acusava a escola de ser responsável pelo desemprego dos anos 30 . Esse malthusianismo escolar assegurava o sentido de valorizar os estudos na medida em que os estudos longos eram socialmente úteis, garantiam empregos àqueles que se lançavam à aventura. A escola não participava da exclusão porque a influência dos diplomas no acesso ao emprego era fraca e controlada.

Com a finalidade de distinguir bem os problemas da exclusão, é preciso esclarecer que esse modo de funcionamento não implica que a sociedade industrial francesa não tenha conhecido a exclusão social. O pleno emprego dos gloriosos anos 30 foi mais a exceção que a regra. A escola republicana se instalou numa sociedade caracterizada por fortes divisões de classes, por desigualdades bem mais marcadas que as de hoje. Havia também camadas operárias e camponesas extremamente pobres e frágeis, categorias que designaríamos hoje como excluídas. Contrariamente à lenda, os imigrantes nem sempre foram bem acolhidos, assimilados ou integrados.

A idade de ouro da escola republicana certamente não era a de uma sociedade francesa integrada, justa e tranqüila. Simplesmente, o tipo de domínio da escola sobre a sociedade visava mais à construção de uma legitimidade política e de uma assimilação nacional que à igualdade de oportunidades e à mobilização da inteligência a serviço da economia. Assim, a escola estava como que protegida da exclusão social. Estava tão mais protegida que os alunos, os quais são hoje qualificados como "excluídos", saíam da escola assim ao concluir a escolaridade obrigatória e não "incomodavam" a vida dos ginásios nem a dos cursos colegiais e muito menos a da universidade.

Esse sistema foi profundamente abalado e novas relações estabeleceram-se entre a escola e a sociedade, fazendo surgir os problemas da exclusão no coração da vida escolar.

\section{Produção e reprodução}

Entre as mudanças ocorridas, é preciso ressaltar o papel da confiança nas teorias do capital humano, quer dizer, na mobilização da escola a serviço do desenvol- 
vimento econômico. O investimento escolar é considerado um investimento produtivo, a prazo a formação é uma força produtiva. $\bigcirc$ malthusianismo escolar é abalado pela longa massificação, no interior da qual a oferta antecipa uma demanda que repousa na velha confiança na educação (Cherkaoui, 1982). Essa massificação baseiase também na convicção de que o desenvolvimento da oferta escolar é um fator de igualdade de oportunidade e de justiça, já que se descortina um sistema que abole as discriminações sociais no ingresso.

Todas as grandes pesquisas e as grandes teorias desenvolvidas pela sociologia da educação demonstram obstinadamente os limites dessa crença. Após a década de 60, todas colocam em evidência o peso dos processos de seleção escolar propriamente dita. É o modelo da reprodução que se impõe globalmente, afirmando que a massificação escolar não reduz as desigualdades escolares, que "reproduzem" largamente as desigualdades sociais. Quaisquer que sejam as nuanças introduzidas nessa análise, o mesmo fato se impõe a todos: é a própria escola que opera as grandes divisões e as grandes desigualdades. Ou seja, as igualdades sociais comandam diretamente a entrada nas carreiras escolares e os próprios processos escolares produzem essas desigualdades que, por sua vez, reproduzem as desigualdades sociais. O sistema está fechado. Abrindo-se, a escola não é mais "inocente", nem é mais "neutra"; está na sua "natureza" reproduzir as desigualdades sociais produzindo as desigualdades escolares.

Alguns autores, como Jencks ( 1979) e Boudon (1973), contestaram esse tipo de análise, colocando em evidência a distância existente entre as desigualdades escolares e as desigualdades sociais em razão da diferença entre as taxas de produção de diplomas e as dos empregos qualificados. Colocam assim o problema da "inflação" dos diplomas provocada pela massificação. Entretanto, embora isso se oponha intelectualmente às razões precedentes, esse tipo de teoria não chega a conclusões opostas e coloca em evidência certos efeitos perversos da massificação. Ainda que a noção de inflação dos diplomas deva ser examinada com prudência (Baudelot, Glaude, 1989; Passeron 1982), é evidente que a influência dos diplomas no acesso ao emprego intensificou-se sensivelmente e que o valor dos diplomas experimentou um movimento crescente.

É associando os dois modelos que se compreende melhor como as relações estruturais da escola e da sociedade se transformaram. De um lado, a escola de massas não é a escola da igualdade; de outro, a massificação que aumenta a prevalência dos diplomas no ingresso ao emprego. Assim, a exclusão escolar, considerada sob o ângulo de um fracasso escolar importante, provoca ipso facto uma relativa exclusão social. E numa sociedade em que mais de 10\% da população 
economicamente ativa são desempregados, os mais desqualificados do ponto de vista da escolarização têm todas as chances de conhecer a exclusão social. O movimento crescente dos diplomas aumenta a exclusão escolar relativa dos não diplomados, que, por sua vez, se deparam com a exclusão provocada pela crise do emprego. Assim, dois fenômenos relativamente independentes, que afetam as relações de produção e as relações de reprodução, encontram-se ligados um ao outro. Para dar a essa análise uma imagem "concreta": a seletividade escolar encaminha os alunos mais fracos para as trajetórias menos qualificadas, o que, por sua vez, aumenta suas "chances" de desemprego e de precariedade. No outro extremo, os diplomas nos níveis mais elevados oferecem uma proteção relativa diante do desemprego. Na medida em que a reprodução não é uma fotocópia exata das desigualdades sociais, é possível ver bem como a escola desempenha um papel autônomo na formação dos mecanismos de exclusão, uma vez que o aluno de meio favorecido que fracassa na escola é ameaçado de exclusão, enquanto o bom aluno de meio desfavorecido vê aumentar suas chances de inserção profissional. Como um e outro desses percursos não são estatisticamente raros numa escola de massas, é importante que se interrogue sobre o próprio papel da escola.

\section{OS MECANISMOS DA EXCLUSÃO ESCOLAR}

A análise do papel da escola nos mecanismos da exclusão escolar implica isolar, evidentemente de maneira teórica e abstrata, os mecanismos e os fatores pelos quais a escola "acrescenta", alia fatores de desigualdade e de exclusão que ultrapassam a simples reprodução das desigualdades sociais. Trata-se dos diversos "efeitos" escolares que remetem à própria ação da escola. Pode-se sensatamente pensar que, se a soma desses "efeitos" não constitui nem a única nem a principal causa da desigualdade e da exclusão, representa entretanto um papel que não pode ser negligenciado.

\section{Os processos escolares}

Entre as conseqüências diretas da massificação escolar, é preciso considerar o conjunto dos mecanismos de diferenciação interna que estrutura o sistema. A oferta escolar não é homogênea e nem produz sempre o mesmo desempenho; não tem sempre a mesma eficácia.

O primeiro mecanismo de diferenciação é o desenvolvimento de percursos construídos muito mais de acordo com os critérios de desempenho que segundo 
escolhas de orientação verdadeira e com os "gostos" dos alunos. De maneira relativamente precoce, este jogo inscreve os alunos em percursos escolares de desempenho desigual e, ao longo dos cursos, as diferenças aumentam. Assim, observa-se que os alunos com dificuldades são orientados para trajetórias escolares mais ou menos desvalorizadas no interior de uma hierarquia extremamente rígida, que impede, quase por completo, o retorno para as carreiras honrosas ou prestigiadas.

Numa escola de massa cada vez mais complexa e cada vez menos legível, esse mecanismo de tratamento e de aprofundamento das distâncias é reforçado por todos os processos implícitos que organizam o "mercado" escolar. Às desigualdades formais, cujo jogo é explícito, somam-se os efeitos das decisões tomadas ao redor do jogo. Pensemos nas conseqüências das escolhas das escolas, que reforçam a concentração dos alunos menos favorecidos e com desempenho pior em certos estabelecimentos e, no interior destes, em certas turmas, em razão das escolhas de línguas por exemplo (Ballion, 1982). Assim, a regra explícita é desviada em prol de mecanismos que reforçam as desigualdades sociais e escolares. $\bigcirc$ mesmo se passa com a escolha para a formação das classes homogêneas. Estas (DuruBellat, Mingat, 1997) não aumentam muito o desempenho dos melhores alunos, mas enfraquecem nitidamente aquele dos alunos mais fracos. Pode-se assim evocar os mecanismos, mais sutis ainda, relativos às decisões que beneficiam sempre os alunos mais favorecidos, cujo desempenho é por antecipação considerado meIhor já que eles se beneficiariam de um suporte familiar mais eficaz (Duru-Bellat, Mingat, 1985).

No final das contas, os alunos mais favorecidos socialmente, que dispõem de maiores recursos para o sucesso, são também privilegiados por um conjunto de mecanismos sutis, próprio do funcionamento da escola, que beneficia os mais beneficiados. Essas estratégias escolares aprofundam as desigualdades e acentuam a exclusão escolar na medida em que mobilizam, junto aos pais, algo que não é só o capital cultural, este entendido como um conjunto de disposições e de capacidades, especialmente lingüísticas. Apela a competências muito particulares referentes aos conhecimentos das regras ocultas do sistema. A escola espera que os pais sejam pessoas informadas, capazes de orientar judiciosamente seus filhos e ajudá-los com eficácia nas suas tarefas. Ao mesmo tempo, fica claro que essa expectativa é cada vez maior e situa-se cada vez mais cedo. Quanto mais os métodos pedagógicos são "ativos", mais eles mobilizam os pais, seus recursos culturais e suas competências educativas. 


\section{O deslocamento das pesquisas}

Imperceptivelmente, a sociologia da reprodução foi substituída pelo estudo dos problemas sociais na escola e pela análise dos mecanismos internos à escola. Com freqüência, a microssociologia tem substituído aquela de dados mais globais. A geografia social da escola pouco a pouco se transformou, com a concentração dos problemas sociais nos bairros "difíceis". Para que nos convençamos disso, basta observar rapidamente as transformações do vocabulário dos atores e da instituição. O problema das escolas e dos alunos "difíceis" se impôs, em poucos anos, como o ponto no qual se focaliza o conjunto dos problemas sociais: periferias, desemprego, imigração, delinqüência, violência, abandono escolar. No vocabulário dos atores, o aluno proveniente da classe operária foi substituído pelo aluno difícil e com dificuldade, que é definido menos por sua situação de dominação do que por sua exclusão. Os professores mudaram o vocabulário: as crianças do povo para as quais a escola deveria assegurar a igualdade de oportunidades são substituídas pelos alunos das regiões "sensíveis", que é importante integrar à sociedade. Lá onde se via um filho de operário, se vê um "caso social". Pela primeira vez, políticas de discriminação positiva são esboçadas com configuração das Zonas de Educação Prioritárias ZEP*** - incentivos são propostos aos professores que nelas trabalham, formações especiais são acionadas... Em resumo, a escola transformou-se e transformou suas representações com a emergência do problema da exclusão.

São incontáveis os livros, as pesquisas e os artigos que tratam desse problema. Evidentemente, como se trata de um "problema", ele é construído tanto pela "realidade" das condutas quanto pelas respostas políticas. $\bigcirc$ tema da violência escolar solidifica esse conjunto (Debarbieux, 1996). Não somente esses trabalhos descrevem as condutas violentas ou percebidas como tais pelos professores, como discutem a função socializadora da escola, da civilização, como uma maneira de viver junto, de construir uma disciplina, de compartilhar direitos e deveres. A violência e as desordens escolares introduzem uma reflexão sobre a função cívica da escola nos contextos em que ela se confronta com a exclusão, com a presença maciça de crianças originárias da imigração, com o declínio da crença na utilidade dos estudos. Payet ( 1995 ) fez a etnologia dos "maus alunos" dos ginásios da periferia, mostrando em particular como o racismo e as agressões pontuam as relações entre os alunos e entre os alunos e os professores. Ballion (1993) estudou as respostas das escolas de

* Zonas de periferia urbana nas quais se concentram as populações com características de exclusão (N. da E.). 
ensino médio aos diversos tipos de desordens escolares. Outros estudos analisaram a relação com o conhecimento dos alunos dos ginásios "difíceis", mostrando especialmente como se constrói, ou não se constrói, um sentido para esse conhecimento (Charlot, Bautier, Rochex, 1992). Alguns estudos se detiveram nas ZEP (Glasman, 1992; Meuret, 1994; Wieviorka, 1993). Na medida em que os municípios e os departamentos ${ }^{* * *}$ intervêm fortemente nas construções das políticas escolares locais, alguns estudos observam as relações, novas na França, entre a escola e os diversos poderes locais (Henriot-van-Zanten, Payet, Roulleau-Berger, 1994).

Seria inútil querer dar conta aqui de todos os trabalhos que, de uma maneira ou de outra, trataram diretamente do tema da exclusão e da escola. Esses trabalhos se diferenciam bastante da longa tradição de estudo das desigualdades escolares. Diferenciam-se, de início, metodologicamente, ao abandonar a análise das grandes séries estatísticas em proveito de abordagens mais etnográficas, centradas na descrição e na análise das práticas e das relações dos atores escolares. Os próprios alunos, durante muito tempo abandonados pela sociologia da educação, dominada pelo paradigma da reprodução, são o assunto principal desses estudos. Mas a inflexão é mais sensível ainda em termos de problemática. A questão é menos relativa às desigualdades que à socialização escolar. Confrontada com a exclusão social, a escola é levada a se interrogar a respeito de uma de suas "funções" fundamentais: sua capacidade de integrar os indivíduos num quadro institucional e cultural, e isso cada vez mais claramente desde que os problemas da exclusão vêm se cruzando com os da imigração. Desse ponto de vista, pode-se afirmar que o encontro da exclusão social e da escola renovou profundamente a sociologia da educação.

\section{A escola questionada}

Dois grandes temas podem ser extraídos do conjunto dessas pesquisas, sem que se pretenda evidentemente esgotar sua riqueza.

$\bigcirc$ primeiro consiste em evidenciar a diversidade das respostas oferecidas pela escola aos alunos de bairros "difíceis". Para além da homogeneidade da forma escolar e do caráter às vezes ritualista dos projetos pedagógicos, percebe-se que os professores e os estabelecimentos oferecem, na realidade, quadros educativos bastante diversos. Por exemplo, certas escolas se deixam invadir pela violência dos

*** Departamentos na França são grandes regiões administrativas que correspondem grosso modo aos estados, sem porém ter as prerrogativas que estes possuem nos regimes federativos (N. da E.). 
bairros, enquanto outras resistem eficazmente. Com freqüência também as respostas institucionais concretas são bastante distanciadas dos programas e dos princípios declarados e dependem do grau de mobilização, de coerência e de engajamento das equipes educativas.

O segundo eixo das conclusões revela o aprofundamento da distância cultural e social que separa os professores e a sua clientela. $\bigcirc$ acordo latente que ligava a escola à sociedade se desestabilizou muito. As expectativas implícitas das famílias não são mais congruentes com os projetos da escola, provocando assim o sentimento de uma crise de legitimidade da escola. Essa crise está relacionada ao peso do fracasso escolar na experiência dos pais, às suas expectativas desmesuradas, mas, sobretudo, à percepção de um declínio da utilidade social dos diplomas. Em sentido contrário, certos estudos evidenciam os mecanismos de mobilização familiar que condicionam o sucesso escolar das crianças originárias da imigração (Zéroulou, 1988). Em todos os casos, as abordagens em termos de deficiências culturais parecem insuficientes.

Mas além de observações e conclusões "técnicas", os estudos relativos à exclusão escolar participam de uma série de debates fundamentais sobre as mutações do sistema escolar na França. Várias questões se apresentam de maneira recorrente. Como renovar a aprendizagem da cidadania numa escola que parece às vezes como a última instituição ainda presente nos bairros difíceis? Que lugar reservar às culturas e às especificidades das crianças de origem estrangeira num modelo escolar universalista e republicano? Em que medida a autonomia, relativa, dos estabelecimentos aprofunda ou atenua as desigualdades? Como os currículos e os métodos pedagógicos devem transformar-se a fim de atenuar a exclusão escolar? Qual é a eficácia das políticas de discriminação positiva - a das ZEP, a ajuda para as tarefas, a formação de mediadores? Faz parte da vocação da escola resolver os problemas sociais? Todas essas perguntas renovam e reorientam a sociologia da educação, participam de debates profissionais e políticos, mostrando que a escola não é apenas uma caixa-preta que registra as desigualdades sociais de maneira "neutra". Sem formulá-las de maneira explícita, a escola é hoje perpassada pelos questionamentos fundamentais sobre os princípios de justiça e de eqüidade. Deve-se compreender que, no contexto francês, todos esses questionamentos adquirem um relevo particular, pois o modelo escolar que se constituiu depois de um século é considerado como o amálgama de um conjunto de valores e de princípios aos quais a sociedade e a nação se identificaram profundamente. Assim, os debates que poderiam parecer simplesmente "técnicos" mobilizam imediatamente paixões e interesses ideológicos que ultrapassam amplamente o quadro da escola. $\bigcirc$ problema da exclusão 
escolar se transforma em debate político central. As "polêmicas", como a do véu islâmico, a da violência dos alunos, não são polêmicas estritamente escolares.

\section{A EXPERIÊNCIA DA EXCLUSÃO O sujeito ameaçado}

O problema da exclusão escolar não se limita ao núcleo dos alunos com grande dificuldade. Pode-se considerar que ele provoca um efeito de halo sobre o conjunto da experiência escolar na medida em que aparece como uma ameaça difusa de exclusão relativa e revela uma contradição essencial da escola quanto ao lugar que é reservado ao sujeito e a suas responsabilidades (Dubet, 1991; Dubet, Martuccelli, 1996). De fato, o problema da exclusão não é apenas saber, de maneira mais ou menos incisiva, quem é excluído, mas de conhecer também os processos e os efeitos dessa exclusão sobre os atores.

A escola democrática de massa é definida por uma tensão normativa fundamental, tensão que se transforma em desafio pessoal para os indivíduos, que não conseguem "ganhar" numa competição que postula a igualdade de todos e procura estabelecer condições.

Por um lado, dentro de seus próprios princípios e acompanhando a massificação, a escola afirma a igualdade de todos. Ela não afirma apenas a igualdade de oportunidades, mas a igualdade de talentos e potencialidades. A ideologia do dom recuou sensivelmente e todas as crianças têm, a priori, o mesmo valor, mesmo admitindo que as condições sociais podem afetar o reconhecimento de suas qualidades e o seu desenvolvimento. A massificação reforçou essa crença, que é sobretudo um postulado étnico, cada um tendo o direito, "em princípio", de aspirar a todas as ambições escolares. Esse princípio de igual valor e de igual dignidade dos indivíduos, de igual respeito que lhes é devido, está no centro de uma ética democrática reforçada pelas mutações de representações da criança, que fazem dela um indivíduo, um sujeito, e não apenas um aluno ou ser ainda incompleto. É importante ressaltar que essa representação do sujeito tem algo de "heróico", de difícil e de exigente, pois ela supõe que cada um seja "soberano", dono de si mesmo, responsável por uma vida que não pode mais ser totalmente reduzida a um destino. $\bigcirc$ sujeito da modernidade é o autor de si mesmo, tanto de suas virtudes como de seus vícios.

Por outro lado, não poderia ser diferente, a escola é meritocrática. Ela ordena, hierarquiza, classifica os indivíduos em função de seus méritos, postulando em revanche que esses indivíduos são iguais. Os indivíduos devem portanto perceber- 
se como os autores de seus desempenhos, como seus responsáveis. A escola apresenta-se um pouco à maneira de uma prova esportiva que postula a igualdade dos concorrentes e a objetividade das regras. A ética esportiva é a da responsabilidade dos desempenhos: que vença o melhor!

Durante longo tempo a escola teve a capacidade de reduzir sensivelmente essa contradição e essa prova. Uma vez que o recrutamento social dos alunos era profundamente desigual, do ponto de vista dos atores era sempre possível explicar as desigualdades escolares pelas injustiças sociais ou naturais. Assim, a maioria dos alunos podia sentir-se protegida, preservar sua auto-estima quando os destinos sociais lhe eram contrários. Sabemos também que as aspirações eram fortemente ajustadas às chances objetivas de sucesso e que, de uma certa maneira, as "leis" da reprodução eram antecipadas pelos indivíduos. Esse sistema de regulação não desapareceu inteiramente, mas se enfraqueceu no momento em que a exclusão social e a exclusão escolar se fortaleceram. A subjetividade dos alunos é então dominada por uma contradição do sistema. A exclusão não é somente um fenômeno sistêmico "objetivo", é também uma experiência subjetiva da exclusão vivida potencialmente como uma destruição de si, já que cada um é responsável por sua própria educação, por sua própria aventura. Ou seja, os alunos excluídos estão ameaçados de se sentir destruídos por sua exclusão, que seria o signo de sua própria "nulidade". Em face desse desafio, muitas estratégias podem ser acionadas.

\section{Retraimento}

A mais antiga e a mais silenciosa é a do retraimento. Os alunos malsucedidos descobrem pouco a pouco que seu trabalho "não se paga", que eles não conseguem obter resultados honrosos apesar de seus esforços. Descobrem que as exigências dos professores quanto ao "trabalho insuficiente" são apenas um modo de proteger a dignidade deles. Descobrem assim que os esforços para remediar não são eficazes. Então os alunos decidem não mais fazer o jogo, não mais participar de uma competição na qual eles não têm nenhuma chance de ganhar. Eles se abandonam ao ritualismo escolar, ao respeito exterior das regras escolares ao mesmo tempo em que se liberam subjetivamente de qualquer envolvimento escolar (Barrère, 1997). Essa estratégia não é isenta de racionalidade se se admite que ela permite aos alunos preservar sua dignidade, sua auto-estima, já que eles próprios contribuem para sua exclusão. No fundo, trata-se de uma auto-exclusão amena graças à qual os alunos salvam uma parte de sua auto-estima tendo em vista que eles nada fazem para obter êxito. Eles perderam a partida, mas a honra está salva uma vez que eles nada fize- 
ram para ganhar, instruídos por uma longa história de fracassos. Por parte dos professores, essa estratégia de auto-exclusão é percebida como uma crise de motivação, como uma maneira de se proteger dos desafios escolares e escapar às críticas. Certamente esses alunos são aqueles que, por meio de uma saída que não chega a contestar o sistema escolar, questionam mais radicalmente a escola. A lealdade subjetiva à escola é muito ameaçadora para que esses alunos assumam esse risco. Se adotássemos o funcionalismo do pior, que vigorou durante muito tempo na sociologia francesa, poderíamos afirmar que esses alunos só fazem antecipar seus destinos, que eles se excluem subjetivamente antes de o serem objetivamente.

\section{O conflito}

A estratégia do conflito é uma outra maneira de responder às tensões estruturais do sistema. Dentre as violências escolares que são hoje percebidas como o sintoma mais manifesto da exclusão na escola, é importante distinguir várias lógicas e várias significações. Uma delas é sem dúvida a entrada na escola das violências, das desordens e das crises sociais: gangues, roubos, insultos... Nesse sentido, a escola é sem dúvida ameaçada pela exclusão social. Mas existem também violências escolares apresentando-se como reações à violência da escola: agressões contra os professores, roubo de materiais... A explicação para esse tipo de violência não se encontra numa permissividade excessiva nem no uso de rédeas curtas.

Inúmeros alunos sentem seus fracassos como atentados a sua dignidade, a sua honra, a sua "cara". Como não podem explicar esse fracasso por meio de causas sociais são levados a sentir-se como os responsáveis e os culpados, escolhem atribuir essa exclusão escolar, sancionada nas salas de aula e nos estabelecimentos menos categorizados, aos próprios professores. A violência contra a escola e os professores é ao mesmo tempo um protesto não declarado e uma maneira de construir sua honra e sua dignidade contra a escola. A microssociologia dessa reação pode perfeitamente ser descrita em termos goffmanianos de "livrar a cara". Os alunos com características étnicas diferentes e que são, de modo geral, vítimas de um racismo dissimulado, recusam a escola como máquina de exclusão, assim como o faziam os operários ingleses descritos por Willis (1977), que se apoiavam numa cultura operária. Mas enquanto os alunos descritos por Willis opunham o mundo operário àquele da escola, os alunos da periferia opõem o mundo "étnico" de sua experiência àquele da instituição. Entretanto, a cultura operária salvava a cara dos jovens ingleses, enquanto a experiência dos jovens de periferia os expõe diretamente ao julgamento escolar que afirma de maneira incessante a igualdade de todos. 
Evidentemente esse protesto contra a exclusão escolar não é destituído de ambigüidades, não é "consciente e organizado", repousa também num desejo frustrado de assimilação escolar, assemelhando-se mais a um tumulto que a reivindicações... Mas está claro também que essas violências tanto procedem diretamente da exclusão escolar quanto da exclusão social. Neste caso também se pode dizer que as violências dos excluídos antecipam sua exclusão, mas ocorre que essas condutas advêm das situações e das próprias tensões escolares.

Essa análise e essa tipologia sumárias decorrem de numerosas descrições interacionistas que constituem a essência da sociologia da exclusão escolar. Realmente, é preciso escolher um modo de explicação ligando as condutas dos indivíduos às lógicas do sistema. Ora, na maioria dos casos, o interacionismo, tal como é praticado, não se vê obrigado a fazer essas escolhas e a estabelecer esses liames. Acumula observações finas que ou se bastam a si mesmas ou só se tornam significativas quando integradas num quadro explicativo mais amplo. É o que mostrou Forquin ( 1983) a propósito da "nova sociologia da educação" inglesa, que acabou por se fundir às análises funcionalistas mais tradicionais ou mais críticas. O outro cenário é o de um interacionismo radical, que rejeita a própria idéia de estrutura social, no sentido que Ihe deu Goffman, para quem o interacionismo é uma representação global da vida social. Ora, essa posição não me parece aceitável, no mínimo porque os processos de exclusão remetem tanto a processos macrossociais quanto à agregação de condutas individuais regulares. É por essa razão que os processos finos da exclusão devem ser interpretados no quadro de processos mais rudimentares e mais regulares referentes à natureza do sistema. A sociologia não pode ser uma longa sucessão atomizada de monografias, por mais precisas que sejam estas.

Tendemos sempre a perceber as mutações como crises e, conseqüentemente a reduzi-las a suas expressões mais cristalizadas. Assim, tendemos a conceber a exclusão escolar como problemas circunscritos a um conjunto de bairros, estabelecimentos e clientelas "difíceis". Evidentemente, essa percepção não é falsa e muito se aprendeu sobre esses casos na medida em que a demanda de conhecimentos e de estudos se acentuou.

Entretanto, a exclusão é o indicador de uma transformação da escola que ultrapassa amplamente os casos agudos de exclusão. O problema da exclusão nos ensina que as relações da escola e da sociedade se transformaram e que a escola perdeu sua "inocência". Ela própria é o agente de uma exclusão específica que transforma a experiência dos alunos e abre uma crise de sentido nos estudos, às vezes até da legitimidade da instituição escolar. A escola convida, um século após a formação da escola republicana, a nos interrogarmos sobre as finalidades da educa- 
ção. Com efeito, a exclusão escolar é o resultado "normal" da extensão de uma escola democrática de massa que afirma ao mesmo tempo a igualdade dos indivíduos e a desigualdade de seus desempenhos. Nesse sentido, a escola integra mais e exclui mais que antes, apesar de seus princípios e de suas ideologias, e funciona cada vez mais como o mercado, que é, em sua própria lógica, o princípio básico da integração e da exclusão.

\section{REFERÊNCIAS BIBLIOGRÁFICAS}

BALLION, R. Les Consommateurs d'école. Paris: Stock, 1982.

Le Lycée, une cité à construire. Paris: Hachette, 1993.

BARRÈRE, A. Les Lycéens au travail. Paris: PUF, 1997.

BAUDELOT, C.; GLAUDE, M. Les Diplômes se dévaluent-ils en se multipliant? Économie et Statistique, n. 225, 1989.

BOUDON, R. L'Inégalité des chances: la mobilité sociale dans les sociétés industrielles. Paris: Armand Colin, 1973.

CHARLOT, B.; BAUTIER, E.; ROCHEX, J. Y. École et savoir dans les banlieues... et ailleurs. Paris: Armand Colin, 1992.

CHARLOT, B.; FIGEAT, M. Histoire de la formation des ouvriers, 1789-1984. Paris: Minerve, 1985.

CHERKAOUI, M. Les Changements du système éducatif en France, 1950-1980. Paris: PUF, 1982.

DEBARBIEUX, E. La Violence en milieu scolaire. Paris: ESF, 1996.

DUBET, F. Les Lycéens. Paris: Seuil, 1991.

DUBET, F.; MARTUCCELLI, D. À L'école: sociologie de l'expérience scolaire. Paris: Seuil, 1996.

DURU-BELLAT, M.; MINGAT, A. La Gestion de l'hétérogénéité des publics d'élèves au collège. Les Cahiers de L'rredu. Dijon, 1997.

De L'Orientation en fin de $5 \mathrm{e}$. au fonctionnement du collège. Cahiers de L'redu. Dijon, 1985, 1992.

FORQUIN, J.-C. La Nouvelle sociologie de l'éducation en Grande-Bretagne: orientation, apports théoriques, évolution (1970-1980). Revue Française de Pédagogie, n. 63, p.61-79, 1983. 
GLASMAN, D. L'École réinventée? Paris: L' Harmattan, 1992.

HENRIOT-VAN-ZANTEN, A.; PAYET J. P.; ROULLEAU-BERGER, L. L'École dans la ville: accords et désaccords autour d'un projet politique. Paris: L'Harmattan, 1994.

ISAMBERT-JAMATI, V. Crises de la société, crises de l'enseignement. Paris: PUF, 1970.

JENCKS, Ch. Inégalités: influence de la famille et de l'école en Amérique. Paris: PUF, 1979.

LELIĖVRE, C. Histoire des institutions scolaires en France. Paris: Nathan, 1990.

MEURET, D. L'Efficacité de la politique des zones d'éducation prioritaires. Revue Française de Pédagogie, n. 109, 1994.

NICOLET, C. L'/dée républicaine en France. Paris: Gallimard, 1982.

PASSERON, J.-C. L'Inflation des diplômes: remarques à l'usage de quelques concepts analogiques en sociologie. Revue Française de Sociologie, n. 23, 1982.

PAYET, J.-P. Collèges de banlieue: ethnographie d'un monde scolaire. Paris: Méridien Klincksieck, 1995.

PROST, A. Histoire de l'enseignement en France, /800- 1967. Paris: Armand Colin, 1967.

TANGUY, L. L'Introuvable relation formation/emploi. Paris: La Documentation Française, 1986.

WIEVIORKA, M. (éd.) L'École et la ville. Bordeaux: Cadis, 1993.

WILLIS, P. Learning to labor. how working class kids get working class jobs. Farnborough, England: Saxon House, 1977.

ZÉROULOU, Z. La Réussite scolaire des enfants d'immigrés: l'apport d'une approche en termes de mobilisation. Revue Française de Sociologie, n. 29, 1988.

Recebido em: julho 2002

Aprovado para publicação em: março 2003 